\title{
Absence of Functional LIN28B Mutations in a Large Cohort of Patients with Idiopathic Central Precocious Puberty
}

\author{
Acácio P. Silveira-Neto ${ }^{\mathrm{a}}$ Leticia Ferro Leal ${ }^{\mathrm{b}}$ Amy B. Emerman ${ }^{\mathrm{e}}$ \\ Katherine D. Henderson ${ }^{c}$ Elena Piskounova ${ }^{\mathrm{e}}$ Brian E. Henderson ${ }^{d}$ Richard I. Gregory

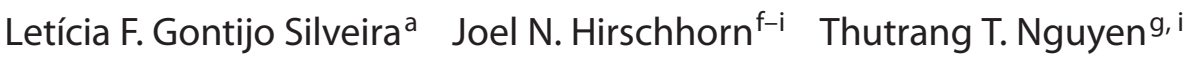 \\ Daiane Beneduzzi ${ }^{a} \quad$ Cintia Tusset $^{\mathrm{a}} \quad$ Ana Claudia S. Reis $^{\mathrm{b}}$ Vinicius N. Brito ${ }^{\mathrm{a}}$ \\ Berenice B. Mendonca ${ }^{a}$ Mark R. Palmert ${ }^{j} \quad$ Sonir R. Antonini ${ }^{b} \quad$ Ana Claudia Latronico ${ }^{a}$ \\ aUnidade de Endocrinologia do Desenvolvimento, Laboratório de Hormônios e Genética Molecular/LIM42, \\ Hospital das Clínicas da Faculdade de Medicina da Universidade de São Paulo, and b Departamento de Puericultura \\ e Pediatria, Faculdade de Medicina de Ribeirão Preto da Universidade de São Paulo, São Paulo, Brazil; 'Department \\ of Population Sciences, City of Hope National Medical Center, Duarte, Calif., dDepartment of Preventive Medicine, \\ Keck School of Medicine, University of Southern California, Los Angeles, Calif., e Department of Biological \\ Chemistry and Molecular Pharmacology, Harvard Medical School, Harvard Stem Cell Institute, The Stem Cell \\ Program at Children's Hospital, f Department of Genetics, Harvard Medical School, 9 Division of Genetics and Center \\ for Basic and Translational Obesity Research, Children's Hospital Boston, and h'Division of Endocrinology, Children's \\ Hospital Boston, Boston, Mass., and 'Cambridge Center, Cambridge, Mass., USA; 'Division of Endocrinology, \\ The Hospital for Sick Children and The University of Toronto, Toronto, Ont., Canada
}

\section{Key Words}

LIN28B gene $\cdot$ Central precocious puberty $\cdot$ Let-7

microRNA $\cdot$ Early menarche $\cdot$ Late menarche

\begin{abstract}
Aim: To investigate $L I N 28 B$ gene variants in children with idiopathic central precocious puberty (CPP). Patients and Methods: We studied 178 Brazilian children with CPP (171 girls, $16.8 \%$ familial cases). A large multiethnic group (1,599 subjects; Multiethnic Cohort, MEC) was used as control. DNA analysis and biochemical in vitro studies were performed. Results: A heterozygous LIN28B variant, p.H199R, was identified in a girl who developed CPP at 5.2 years. This variant was absent in 310 Brazilian control individuals, but it was found
\end{abstract}

in the same allele frequency in women from the MEC cohort, independent of the age of menarche. Functional studies revealed that when ectopically expressed in cells, the mutant protein was capable of binding pre-let-7 microRNA and inhibiting let-7 expression to the same extent as wild-type Lin28B protein. Other rare LIN28B variants (p.P173P, c.198+ 32_33delCT, g.9575731A $>C$ and c.-11C $>$ T) were identified in CPP patients and controls. Therefore, no functional mutation was identified. Conclusion: In vitro studies revealed that the rare LIN28B p.H199R variant identified in a girl with CPP does not affect the Lin28B function in the regulation of let-7 expression. Although LIN28B SNPs were associated with normal pubertal timing, rare variations in this gene do not seem to be commonly involved in the molecular pathogenesis of CPP.

Copyright @ 2012 S. Karger AG, Basel

\section{KARGER}

Fax +4161306 1234

E-Mail karger@karger.ch

www.karger.com
C) 2012 S. Karger AG, Basel

1663-2818/12/0783-0144\$38.00/0

Accessible online at:

www.karger.com/hrp
Ana Claudia Latronico, MD

Av. Dr. Eneas de Carvalho Aguiar

$155-2^{\circ}$ andar, Bloco 6

São Paulo 05403-900 (Brazil)

Tel. +55 112661 7512, E-Mail anacl@usp.br 


\section{Introduction}

Central precocious puberty (CPP) results from the premature activation of the hypothalamic-pituitary-gonadal axis before the age of 8 years in girls and 9.5 years in boys [1]. CPP has a striking predominance among girls, and most of these cases show no organic abnormality in the central nervous system, being considered as idiopathic $[2,3]$. It is known that genetic factors play a fundamental role in the timing of pubertal onset, as illustrated by the similar age at menarche among members of an ethnic group and in mother-daughter, monozygotic-twin, and sibling pairs [4]. Interestingly, a $27.5 \%$ prevalence of familial cases has been reported in CPP, suggesting a genetic origin [5]. Segregation analysis in these families suggested autosomal dominant transmission with incomplete, sex-dependent penetrance [5]. Furthermore, activating mutations in kisspeptin and its receptor, a potent GnRH stimulator system, have recently been described as genetic causes of CPP in isolated cases $[6,7]$.

In 2009, four independent genome-wide association studies identified genetic variations clustered at $6 \mathrm{q} 21$ near or within the LIN28B gene, associated with timing of puberty [8-11]. LIN28B is a human homolog of lin-28 of the nematode Caenorhabditis elegans, which was originally identified as a heterochronic regulator of developmental timing [12]. Deleterious mutations in lin-28 produce an abnormal rapid tempo of development through larval stages to adult cuticle formation [13]. Conversely, enhancement of lin-28 expression by deletion of regulatory elements delays larval stage progression [12]. In fact, transgenic mice overexpressing Lin28a exhibited increased body size, crow-rump length and delayed onset of puberty [14].

The lin-28 genes regulate the biogenesis of let-7 microRNA (miRNA) family members, controlling the time of developmental events [15]. In vertebrates, let-7 miRNA controls Lin-28 translation, whereas Lin-28 is required for the correct timing of let-7 expression during normal development, constituting an autoregulatory loop [16]. In the present study, we hypothesized that rare variants in LIN28B could cause more dramatic changes in the timing of puberty, resulting in new organic CPP.

\section{Patients and Methods}

We studied 178 patients with CPP (171 girls and 7 boys) recruited from University Hospitals from Sao Paulo University Medical School in Sao Paulo and Ribeirao Preto, Brazil. The protocol was approved by the Ethical Committees of Sao Paulo Uni- versity. Written informed consent was obtained from all patients and/or their parents. The selected patients started puberty before 8 years in girls and 9.5 years in boys, with mean age at start of puberty of $5.4 \pm 2$ years (0.1-7.9). All patients had pubertal basal and/or GnRH-stimulated LH levels, advanced bone age and normal central nervous system magnetic resonance imaging. In 30 patients (16.8\%), familial history of CPP was recalled.

Two distinct control populations were studied for LIN28B variant analyses. One population consisted of 310 Brazilian adults who had normal pubertal development at appropriated chronological age, according to a systematic questionnaire. In addition, a group of 1,599 women from the Multiethnic Cohort (MEC) was also studied [17]. They had normal and spontaneous puberty and were divided into two subgroups according to the age of menarche: early (less than 11 years) or late (at 15 years or older). Ancestry informative markers were previously genotyped in this panel and individuals whose self-reported racial/ethnic group did not match their estimated genetic ancestry were removed. Fourteen women who may have started oral contraceptives before their first period were excluded from analysis. In total, 1,599 women had suitable genotype and phenotype data for analysis.

\section{DNA Analysis}

Genomic DNA was extracted from peripheral blood leukocytes using standard procedures. The four exons and boundary regions of LIN28B (GenBank accession number: MIM 611044) were amplified by PCR and automatically sequenced in all patients with idiopathic CPP. In addition, the proximal promoter region $(0.4 \mathrm{~kb})$ was studied in 99 patients with CPP and in 110 Brazilian controls. Primers and PCR conditions are available upon request. All sequences were analyzed using CodonCode Aligner v. 3.5.2 $2^{\mathrm{TM}}$. Genetic variations found in the patients were confirmed in both strands. In addition, the variations found in the patients were screened in control DNA samples. The splice predictor software program, NNSplice version 0.9 (www.fruitfly. org/seq_tools/splice.html) was used for analyzing aberrant RNAs.

The genotyping of a $L I N 28 B$ variant (c.799A $>$ G) in the MEC samples was performed using the Sequenom MassARRAY platform and the iPLEX genotyping protocol (Sequenom, Inc., San Diego, Calif., USA).

\section{Functional Studies}

Cloning

Human LIN28B was cloned into pFLAG-CMV2 vector (Sigma). LIN28B H199R was generated by site-directed mutagenesis using the QuickChange system (Stratagene). Pri-let-7g expression plasmid and the pSiCheck2-luciferase reporter containing the let7 target sites were previously reported [15].

\section{Cell Culture and Transfections}

HEK293 and HeLa cells were maintained in DMEM (Gibco, Invitrogen), supplemented with 10\% FBS, Pen/Strep, L-glutamine and non-essential amino acids (Gibco, Invitrogen). All transfections were performed with lipofectamine (Invitrogen) per manufacturer's instructions.

Immunoprecipitation and Western Blotting

Whole-cell lysates were prepared using lysis buffer: $20 \mathrm{mM}$ Tris/pH 8.0, $137 \mathrm{~mm} \mathrm{NaCl,} 1$ mM EDTA, 1\% Triton X100, 10\% glycerol, $1.5 \mathrm{mM} \mathrm{MgCl}_{2}, 1 \mathrm{mM}$ DTT, with protease inhibitors 
Fig. 1. a Nucleotide sequence of $L I N 28 B$ gene showing the wild type and the variant identified in a girl with CPP. b Detailed LIN28B amino acid sequence alignment among species showing that histidine in position 199 is highly conserved among mammals. The following were sequence sources: Homo sapiens (GenBank NP_002247.2), Pan troglodytes (GenBank XP_514123.1), Gorilla gorilla, Macaca mulatta(GenBank XP_001098284.1), Bos taurus (GenBank XP_872566.1), Mus musculus (GenBank NP_839991.1) and Rattus norvegicus (GenBank NP_859043.1).

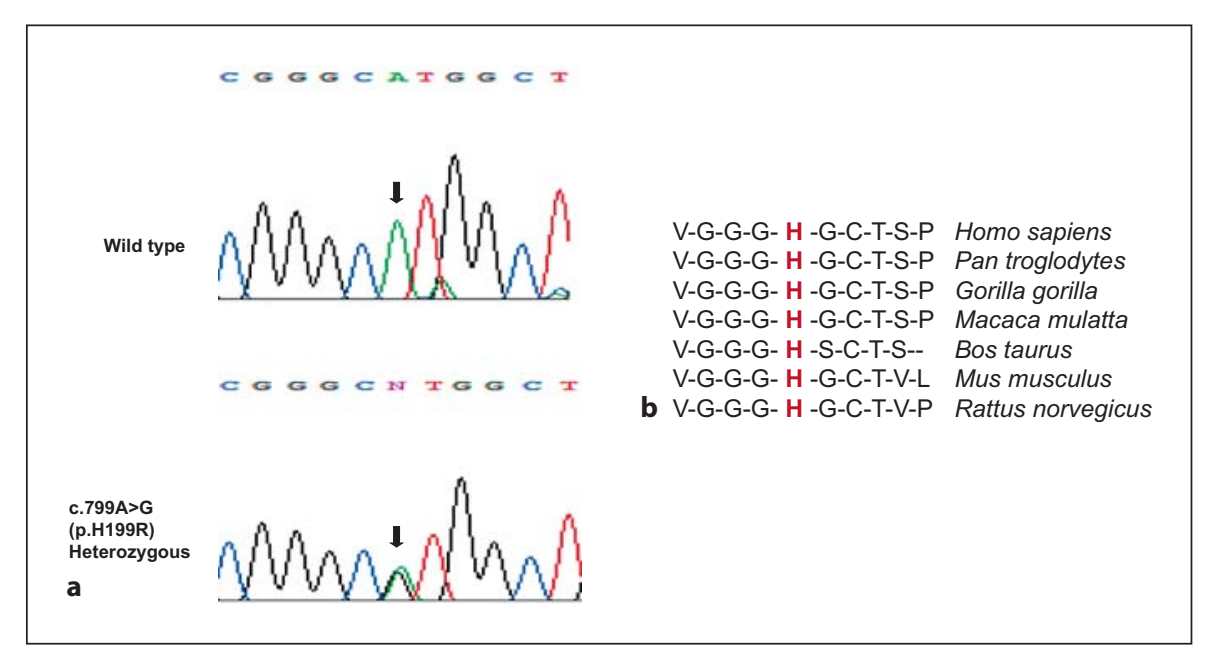

(Roche). Flag immunoprecipitations were done using Flag agarose beads (Sigma) for $90 \mathrm{~min}$ at $4^{\circ} \mathrm{C}$. Beads were washed with buffer containing $300 \mathrm{mM} \mathrm{KCl}$. Elutions were performed with Flag peptide (Sigma). Affinity eluate was resolved on 4-12\% TrisGlycine-SDS gels (Invitrogen) and transferred to Immobilon-P PVDF Membrane (Millipore). Anti-Flag-HRP Antibody (Sigma, A8592) was used at 1:1,000 dilution in 5\% milk for $1 \mathrm{~h}$.

Electromobility Shift Assay

Electromobility shift assay (EMSA) was performed using a synthetic 5 '-end radiolabeled 78-nt pre-let-7g RNA with final concentration of $0.5 \mu \mathrm{M}$ [18]. Affinity-purified wild-type and mutant Lin28B proteins from human cells were used. Complexes were resolved on native 3.5 or $5 \%$ polyacrylamide gels and visualized by autoradiography. Band intensities of scanned gels were quantified using ImageJ software and used to calculate percentage of probe bound. Percent active protein was determined using stoichiometric binding reactions.

RNA Extraction and Real-Time PCR

RNA was harvested from transfected HEK293 cells using Trizol (Invitrogen) per manufacturer's instructions. U18 small nuclear RNA was used as a normalizer. TaqMan microRNA assays (Applied Biosystems) were used to quantify mature miRNA expression as described previously [19].

\section{Luciferase Assay}

HeLa cells do not express endogenous Lin28B, as previously demonstrated [20]. These cells were grown on 6-well plates, cotransfected with $1 \mu \mathrm{g}$ of the indicated expression plasmids together with $1 \mu \mathrm{g}$ let-7-reporter gene. Cells were harvested $48 \mathrm{~h}$ after transfection. All transfections were done in triplicate. Luciferase levels were analyzed using the Dual Luciferase Assay System (Promega) that contains an internal control. A siCHECK2 vector that expresses both firefly luciferase and the renilla luciferase from the same plasmid were used. The vector was engineered to contain a let-7 complementary site between the renilla luciferase open reading frame and the polyA site. This reporter allowed monitoring of let-7 activity in cells by monitoring relative luciferase levels in the presence or absence of Lin28B expression.

\section{Statistical Analysis}

Age at menarche was analyzed as a dichotomous trait using the software package PLINK v1.07 [21]. Because the women from the MEC represented different racial/ethnic groups, the groups were analyzed separately using Fisher's exact test for each group in which the variant allele was observed. The results were then combined in a sample size-weighted meta-analysis using the program METAL [22]. Similar results were obtained using regression with racial/ethnic groups as a covariate, along with estimated genetic ancestry as previously described [22].

\section{Results}

\section{DNA Analysis of LIN28B Gene in CPP}

A heterozygous c.799A $>G$ transition in exon 4 of the $L I N 28 B$ gene, resulting in substitution of arginine for a histidine at position 199 (p.H199R), in the carboxy-terminal region of LIN28B was identified in one girl who developed precocious puberty at 5.2 years (fig. 1a). Both parents had normal pubertal development. Her father carried the same heterozygous variant and the mother was homozygous for the wild-type allele. The c.799A $>\mathrm{G}$ variant was not found in 310 Brazilian controls.

In the 5'UTR, the heterozygous c.-11C $>\mathrm{T}$ substitution was identified in two patients with CPP and in one Brazilian control subject. In another patient, we identified an intronic heterozygous 2-nt deletion (c.198+32_ 33 delCT), which was not identified in 110 Brazilian controls. The presence of the c.198+32_33delCT variant did not affect the splice site strength score, suggesting no aberrant splicing. In intron 2 , we identified the previously reported polymorphism g.9575731A $>$ C (rs17065417, previously known as rs59756390), in the heterozygous state 
Table 1. Genetic variants identified in the $L I N 28 B$ gene in 178 patients with CPP

\begin{tabular}{|c|c|c|c|c|c|}
\hline \multirow[t]{2}{*}{ Variant } & \multirow{2}{*}{$\begin{array}{l}\text { Gene } \\
\text { location }\end{array}$} & \multirow[t]{2}{*}{ Status } & \multicolumn{2}{|c|}{ Variant frequency, \% } & \multirow[t]{2}{*}{ Functional impact } \\
\hline & & & $\mathrm{CPP}$ & controls & \\
\hline c. $-11 \mathrm{C}>\mathrm{T}($ rs76300431) & 5' UTR & heterozygous & $2.0^{\mathrm{a}}$ & $0.9^{\mathrm{b}}$ & unknown (reported SNP) \\
\hline c.198+32_33delCT & intron 2 & heterozygous & $1^{\mathrm{a}}$ & $0^{\mathrm{b}}$ & unlike to affect splicing \\
\hline g.9575731A >C (rs17065417) & intron 2 & heterozygous & $18^{\mathrm{a}}$ & - & unknown (reported SNP) \\
\hline c. $519 \mathrm{C}>\mathrm{T}(\mathrm{p} . \mathrm{P} 173 \mathrm{P})$ & exon 3 & heterozygous & 0.56 & 0 & silent mutation (unlike to affect splicing) \\
\hline c.799A > G (p.H199R) & exon 4 & heterozygous & 0.56 & $0 / 0.5^{c}$ & $\begin{array}{l}\text { it does not affect the function of Lin } 28 \mathrm{~B} \text { in } \\
\text { the regulation of let- } 7 \text { expression }\end{array}$ \\
\hline
\end{tabular}

a Analysis of the $5^{\prime}$ UTR and intron 2 of the Lin $28 B$ gene in 99 patients with CPP. ${ }^{\text {b }}$ Brazilian control subgroup (110 individuals). ${ }^{\mathrm{c}}$ MEC cohort 1,599.

Table 2. Analysis of the $L I N 28 B$ variant c.799A $>$ G (p.H199R) in 1,599 women with early or late age at menarche

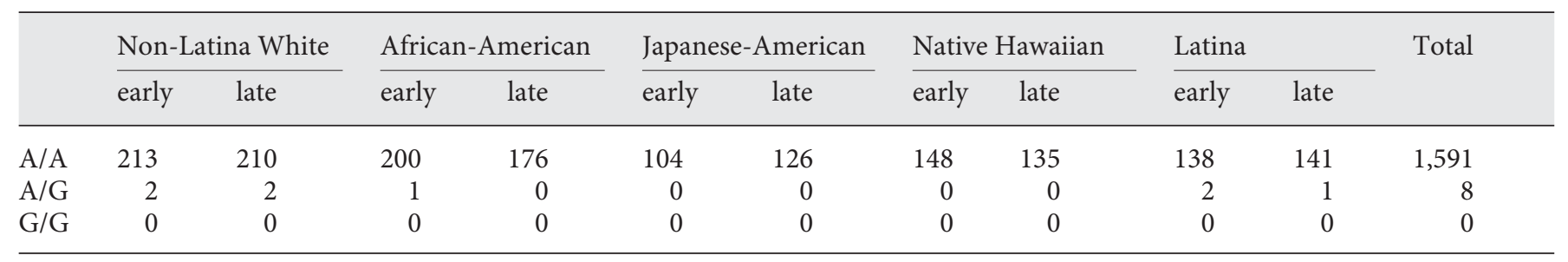

in 18 patients with CPP. Finally, a heterozygous silent variant in exon 3, c.519C $>\mathrm{T}$ (P173P), was identified in one girl with CPP and absent in 110 controls. In silico analysis suggested that this silent variant was also unlikely to result in abnormal splicing. Table 1 summarizes the $L I N 28 B$ variants identified in children with CPP and controls.

\section{Functional Studies}

Both Lin28A and Lin28B were previously shown to block let-7 miRNA processing $[15,23]$. To begin to examine the functional consequences of the p.H199R mutation, we generated plasmids for the overexpression of Flag-tagged wild-type Lin28B as well as the p.H199R variant Lin28B protein. We first examined the expression of these cDNAs and performed Flag affinity purifications from HEK293 cells transfected with the corresponding expression plasmids and analyzed the immunoprecipitate by Western blot. This analysis revealed that both the wild-type and variant Lin28B proteins were expressed at similar levels (fig. 2a). Interestingly, we reproducibly observed a slower migrating band that was detected by Western blot using either anti-Flag antibody (fig. 2a) or a specific antibody for Lin28B detection (data not shown). Strikingly, this slower migrating from of Lin $28 \mathrm{~B}$ was not detected for the H199R variant protein (fig. 2a). The identity of the slower migrating band for the wild-type Lin $28 \mathrm{~B}$ protein was confirmed by large-scale Flag immunoprecipitation and mass spectrometry (data not shown). Together, these data indicate that a portion of Lin28B may be posttranslationally modified and that the H199R variant abolishes this putative modification.

The relative RNA-binding affinity of the wild-type and H199R Lin28B proteins were measured by EMSA using radiolabeled synthetic pre-let-7 RNA. This analysis revealed that the both the wild-type and mutant Lin $28 \mathrm{~B}$ proteins display comparable pre-let-7 RNA-binding affinities (fig. 2b). Next, we assessed the ability of these proteins to inhibit let-7 expression. For these experiments, HEK293 cells were transfected with a plasmid expressing pri-let-7g together with control, Lin28B, or H199R Lin28B expression vectors. We analyzed levels of mature let-7 miRNA expression by quantitative reverse transcriptase PCR (q.RT-PCR). Expression of wild-type or H199R Lin28B protein inhibited the accumulation of mature let$7 \mathrm{~g}$ to a similar extent indicating that these proteins are 
Fig. 2. a Analysis of Flag-immunopurified proteins by Western blot. b EMSA performed with pre-let-7 and the indicated amount of Flag-immunopurified Lin28B and H199R Lin28B proteins. c q.RT-PCR analysis of let-7g expression in transfected HEK293 cells. U18 quantitative RT-PCR was used as a normalizer. The transfection efficiency was confirmed by the observation that mature let-7 increased after prilet-7 transfection. d Luciferase activity assay using a let-7-responsive reporter gene. HeLa cells were cotransfected with indicated expression plasmid together with the let-7-sensitive reporter plasmid. Relative luciferase represents the renilla:firefly ratio normalized to 1 in the absence of Lin28B expression (control).

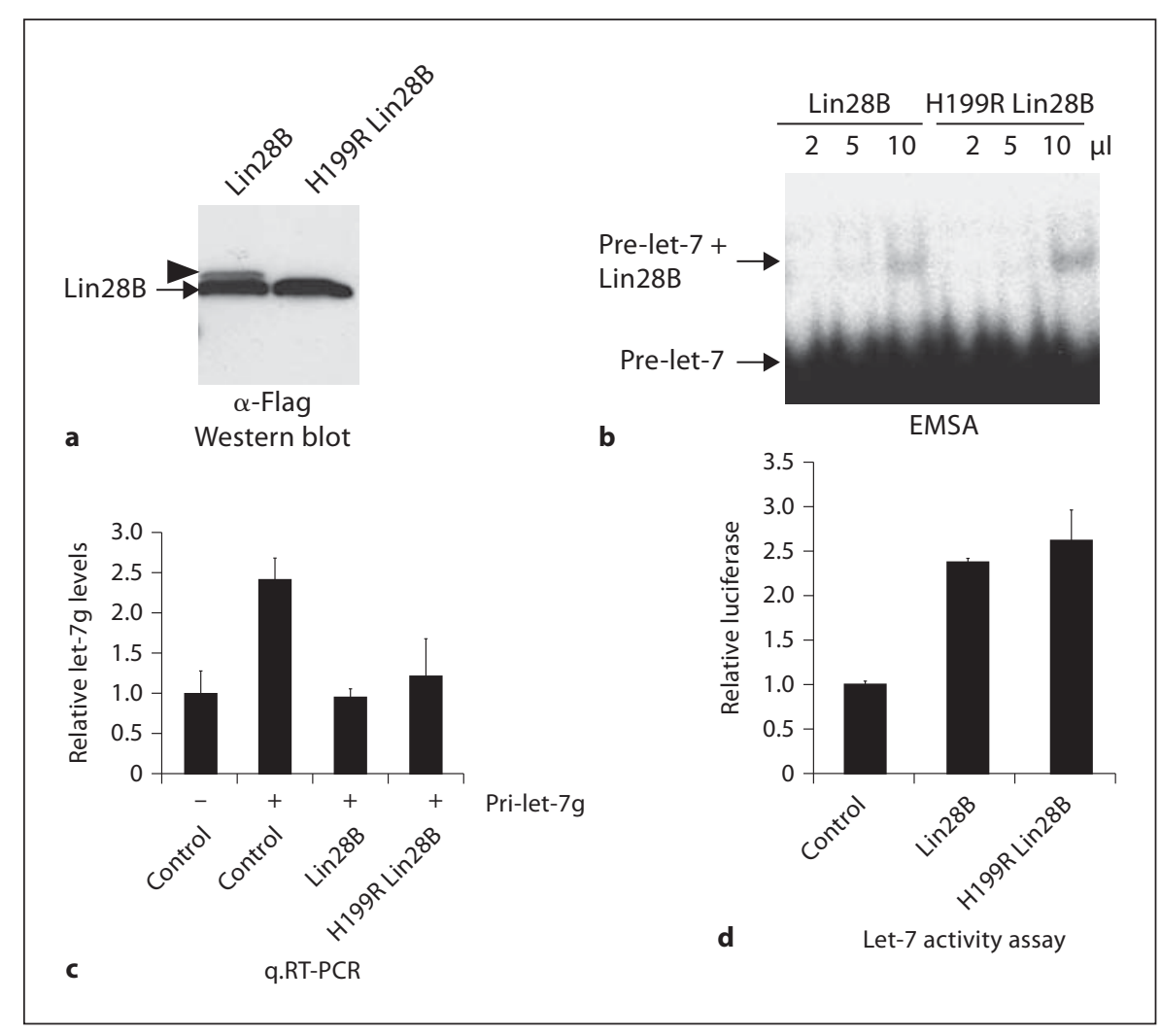

equally capable of blocking let-7 biogenesis in these experiments (fig. 2c).

Finally, to further compare the capacity of wild-type and H199R Lin28B proteins to inhibit the let-7 miRNA pathway, we utilized a let-7-responsive reporter gene assay. For these experiments, we used a luciferase construct engineered to contain functional let-7 target sites in the $3^{\prime}$ UTR. Expression of luciferase from this construct is therefore normally repressed by let-7. Using this system, we found that coexpression of Lin28B together led to the expected de-repression of the let-7 reporter. Furthermore, expression of the mutant p.H199R Lin28B protein led to a comparable de-repression of the let-7-responsive luciferase reporter (fig. 2d). Together, these experiments indicated that the p.H199R variant does not seem to have effect on the ability of the mutant protein to repress let-7 expression.

\section{Screening of the p.H199R in the MEC}

We tested whether the $L I N 28 B$ variant c.799A $>\mathrm{G}$ (p.H199R) was associated with early age at menarche in a panel of 808 women with early age at menarche and 791 women with late age at menarche. Five women with early age at menarche $(0.6 \%)$ and 3 women with late age at menarche $(0.4 \%)$ were heterozygous $(\mathrm{A} / \mathrm{G})$; no cases homozygous for the rare allele $(\mathrm{G} / \mathrm{G})$ were observed (table 2). There was no significant association with early or late age at menarche (overall $\mathrm{p}$ value 0.771 ).

\section{Discussion}

Recently, the first loci with common variation reproducibly associated with population variation in the timing normal of puberty were identified at $6 \mathrm{q} 21$ in or near the LIN28B gene [24]. In the current study, we investigated the role of genetic variants of LIN28B in the extreme phenotype involving early human pubertal onset. A group of 178 Brazilian children with CPP, mostly girls with mean pubertal onset at 5.4 years of age, was selected for sequencing analysis of the promoter and entire coding regions of $L I N 28 B$. Few rare heterozygous variants were identified, including two in the coding region (p.P173P and p.H199R), two intronic (c.198+32_33delCT and g.9575731A >C), and one in the 5'UTR (c.-11 C>T; table 1). 
Among these variants, the p.H199R, identified in a girl with sporadic CPP, was considered a potential functional variant. The histidine at position 199 , located in the carboxy-terminal region of the protein outside the RNAbinding domains, is highly conserved among mammalians (fig. 1b), and it was absent in 310 Brazilian controls. In a previous study, sequencing of the LIN28B gene in 145 Finnish children with constitutional delay of growth and puberty did not identify any allelic variant in LIN28B coding region, indicating that allelic variants in that region are very rare [25]. More recently, the p.H199R variant was identified in one Danish patient with CPP and in one of the 132 controls [26].

Lin 28 binds specifically to the terminal loop region of let-7 precursors, blocking the maturation of let-7 miRNAs in mouse embryonic stem cells and in mouse and human cancer cell lines $[15,18,27]$. Interestingly, increased let-7 gene dosage causes precocious expression of adult fates during larval stages [27]. We hypothesized that inactivating mutations in LIN28B could affect let-7 miRNA repression and consequently stimulate pubertal development in humans. To evaluate if the repression function of the p.H199R variant LIN28B was impaired, we performed in vitro biochemical assays. When ectopically expressed in cells, the mutant protein was capable of inhibiting let-7 miRNA expression to the same extent as wild-type Lin $28 \mathrm{~B}$ protein. Consistent with this finding, we also found that it was capable of binding pre-let-7 miRNA comparable to wild-type Lin28B (EMSA assays). Thus, it seems that this particular variant does not affect the function of Lin28B in the regulation of let-7 expression. Furthermore, this variant is located outside of the domains known to be required for the repression of let-7 miRNA maturation.

Other pleiotropic roles of Lin28 have been demonstrated in physiological and pathological processes. It remains possible that LIN28B has additional gene regulatory functions involved in the control of the timing of puberty in humans. In support of this notion, Lin28A has additional gene regulatory roles in the cell cytoplasm and can directly associate with several different mRNAs, including cell growth and metabolism [28]. In addition, Lin28A and Lin28B are differentially localized in cells, with Lin28B being predominantly nuclear [20]. It would be interesting to identify posttranslational modification(s) of the Lin28B protein that may be responsible for the altered gel migration patterns that we observed for the wild-type Lin28B protein but absent from the H199R protein. Therefore, our functional analysis cannot exclude that the p.H199R variant plays a role in these other

LIN28B Gene Variants in Children with Idiopathic CPP phenotypic traits. Even if the p.H199R variant leads to a yet unidentified functional consequence, its presence in the proband's father argues against it causing CPP. Moreover, the genotypic frequency of the p.H199R (c.799A >G) variant was investigated in 1,599 women with normal pubertal development, who were divided into early $(<11$ years) and late ( $>15$ years) age at menarche. The $G$ allele was identified in a low frequency $(<1 \%)$ in both groups, with no statistical significance difference between the early and late menarche groups. Additionally, the p.H199R variant has been identified as a rare variant in $<1 \%$ of the population in the 1,000 genome pilot project, which provided a deep characterization of human genome sequence variation using different genome-wide sequencing with high-throughput platforms [29]. Taken together, these data suggest that the p.H199R variant does not play a causative role in the CPP phenotype.

Additionally, a heterozygous $\mathrm{C}>\mathrm{T}$ substitution located 11 nucleotides before the translation start site was identified in 2 patients. To our knowledge, the regulatory region of the LIN28B has not yet been characterized. This variation could affect the cis-regulatory control of gene expression; however, as it was also found in one of the control subjects, it is likely to be non-functional. In agreement with this observation, this variation was recently reported in another population, and the reported allele frequency is comparable to the subjects analyzed in this study. In another CPP patient, a 2-nt deletion in intron 2 was found. This variation was not observed in 110 healthy controls. The calculated splice strength score did not change, indicating that this mutation does not result in aberrant splicing. Therefore, it is unlikely that this rare genetic variant affects LIN28B function.

In conclusion, we did not identify causative $L I N 28 B$ mutations in patients with CPP. In vitro biochemical assays revealed that the missense p.H199R, found in one girl with CPP, does not affect the function of Lin28B in the regulation of let-7 expression. Thus, although genome-wide association studies had shown the association of common polymorphisms in $L I N 28 B$ with variations in the timing of normal puberty, our data from a large number of patients with CPP show that mutations in LIN28B do not seem to be commonly involved in the molecular pathogenesis of CPP.

\section{Acknowledgements}

This work was supported by grants from Conselho Nacional de Desenvolvimento Científico e Tecnológico (CNPq) and Funda- 
ção de Amparo a Pesquisa do Estado de São Paulo - FAPESP, process No. 05/04726 to A.C.L., and 08/55953-4 to A.P.S.N. R.I.G. was supported by grants from the US National Institute of General Medical Sciences (1R01GM086386-01A1), The Harvard Stem Cell Institute, and the Emerald Foundation. R.I.G. is a Pew Research Scholar. Work supported by NIH R01-HD048960 to M.R.P., J.N.H., and B.E.H.

\section{Disclosure Statement}

The authors declare that there is no conflict of interest that could be perceived as prejudicing the impartiality of the research reported.

\section{References}

$\checkmark 1$ Carel JC, Leger J: Clinical practice. Precocious puberty. N Engl J Med 2008;358:23662377.

2 Delemarre-van de Waal HA: Secular trend of timing of puberty. Endocr Dev 2005;8:1-14.

- 3 Partsch CJ, Sippell WG: Pathogenesis and epidemiology of precocious puberty. Effects of exogenous oestrogens. Hum Reprod Update 2001;7:292-302.

4 Palmert MR, Boepple PA: Variation in the timing of puberty: clinical spectrum and genetic investigation. J Clin Endocrinol Metab 2001;86:2364-2368.

5 de Vries L, Kauschansky A, Shohat M, Phillip M: Familial central precocious puberty suggests autosomal dominant inheritance. J Clin Endocrinol Metab 2004;89:1794-1800.

-6 Silveira LG, Noel SD, Silveira-Neto AP, Abreu AP, Brito VN, Santos MG, et al: Mutations of the KISS1 gene in disorders of puberty. J Clin Endocrinol Metab 2010;95: 2276-2280.

7 Teles MG, Bianco SD, Brito VN, Trarbach EB, Kuohung W, Xu S, et al: A GPR54-activating mutation in a patient with central precocious puberty. N Engl J Med 2008;358: 709-715.

$>8$ He C, Kraft P, Chen C, Buring JE, Pare G, Hankinson SE, et al: Genome-wide association studies identify loci associated with age at menarche and age at natural menopause. Nat Genet 2009;41:724-728.

-9 Ong KK, Elks CE, Li S, Zhao JH, Luan J, Andersen LB, et al: Genetic variation in LIN28B is associated with the timing of puberty. Nat Genet 2009;41:729-733.

10 Perry JR, Stolk L, Franceschini N, Lunetta KL, Zhai G, McArdle PF, et al: Meta-analysis of genome-wide association data identifies two loci influencing age at menarche. Nat Genet 2009;41:648-650.
-11 Sulem P, Gudbjartsson DF, Rafnar T, Holm H, Olafsdottir EJ, Olafsdottir GH, et al: Genome-wide association study identifies sequence variants on $6 \mathrm{q} 21$ associated with age at menarche. Nat Genet 2009;41:734-738.

12 Moss EG, Lee RC, Ambros V: The cold shock domain protein LIN-28 controls developmental timing in C. elegans and is regulated by the lin-4 RNA. Cell 1997;88:637-646.

13 Ambros V, Horvitz HR: Heterochronic mutants of the nematode Caenorhabditis elegans. Science 1984;226:409-416.

- 14 Zhu H, Shah S, Shyh-Chang N, Shinoda G, Einhorn WS, Viswanathan SR, et al: Lin28a transgenic mice manifest size and puberty phenotypes identified in human genetic association studies. Nat Genet 2010;42:626630.

15 Viswanathan SR, Daley GQ, Gregory RI: Selective blockade of microRNA processing by Lin28. Science 2008;320:97-100.

16 Moss EG, Tang L: Conservation of the heterochronic regulator Lin-28, its developmental expression and microRNA complementary sites. Dev Biol 2003;258:432-442.

-17 Kolonel LN, Henderson BE, Hankin JH, Nomura AM, Wilkens LR, Pike MC, et al: A multiethnic cohort in Hawaii and Los Angeles: baseline characteristics. Am J Epidemiol 2000;151:346-357.

18 Piskounova E, Viswanathan SR, Janas M, LaPierre RJ, Daley GQ, Sliz P, et al: Determinants of microRNA processing inhibition by the developmentally regulated RNA-binding protein Lin28. J Biol Chem 2008;283: 21310-21304

19 Hagan JP, Piskounova E, Gregory RI: Lin28 recruits the TUTase Zcchc11 to inhibit let-7 maturation in mouse embryonic stem cells. Nat Struct Mol Biol 2009;16:1021-1025.

-20 Piskounova E, Polytarchou C, Thornton JE, LaPierre RJ, Pothoulakis C, Hagan JP, et al: Lin28A and Lin28B inhibit let-7 microRNA biogenesis by distinct mechanisms. Cell 2011;147:1066-1079.
21 Purcell S, Neale B, Todd-Brown K, Thomas L, Ferreira MA, Bender D, et al: PLINK: a tool set for whole-genome association and population-based linkage analyses. Am J Hum Genet 2007;81:559-575.

22 Willer CJ, Li Y, Abecasis GR: METAL: fast and efficient meta-analysis of genome wide association scans. Bioinformatics 2010;26: 2190-2191.

23 Newman MA, Thomson JM, Hammond SM: Lin-28 interaction with the Let-7 precursor loop mediates regulated microRNA processing. RNA 2008;14:1539-1549.

24 Elks CE, Perry JR, Sulem P, Chasman DI, Franceschini N, He C, et al: Thirty new loci for age at menarche identified by a metaanalysis of genome-wide association studies. Nat Genet 2010;42:1077-1085.

25 Tommiska J, Wehkalampi K, Vaaralahti K, Laitinen EM, Raivio T, Dunkel L: LIN28B in constitutional delay of growth and puberty. J Clin Endocrinol Metab 2010;95:30633066.

26 Tommiska J, Sorensen K, Aksglaede L, Koivu R, Puhakka L, Juul A, et al: LIN28B, LIN28A, KISS1, and KISS1R in idiopathic central precocious puberty. BMC Res Notes 2011;4:363.

27 Reinhart BJ, Slack FJ, Basson M, Pasquinelli AE, Bettinger JC, Rougvie AE, et al: The 21-nucleotide let-7 RNA regulates developmental timing in Caenorhabditis elegans. Nature 2000;403:901-906.

28 Peng S, Chen LL, Lei XX, Yang L, Lin H, Carmichael GG, et al: Genome-wide studies reveal that Lin28 enhances the translation of genes important for growth and survival of human embryonic stem cells. Stem Cells 2011;29:496-504.

-29 Durbin RM, Abecasis GR, Altshuler D, Auton A, Brooks LD, Gibbs RA, et al: A map of human genome variation from populationscale sequencing. Nature 2010;467:10611073. 